\title{
Influence of Soil Conductivity and Rod-to-Earth Gaps on Lightning Breakdown Voltage and Peak Current of Rod-to-Plane Air Gaps
}

\author{
${ }^{1,2}$ Usama Khaled, ${ }^{3}$ Abderrahmane Beroual, ${ }^{1}$ Salman Alissa, ${ }^{1}$ Omar Aldraimli and ${ }^{1}$ Abdulrahman Abanmi \\ ${ }^{1}$ Department of Electrical Engineering, College of Engineering, King Saud University, \\ 11421 Riyadh, Saudi Arabia \\ ${ }^{2}$ Department of Electrical Engineering, Faculty of Energy Engineering, Aswan University, \\ Aswan, Egypt \\ ${ }^{3}$ Ecole Centrale de Lyon, University of Lyon, AMPERE CNRS UMR 5005, 69134 Ecully, France \\ ukhaled@ksu.edu.sa
}

\begin{abstract}
This study deals with the influence of soil conductivity and a rod-to-earth electrode gap on lightning impulse voltages. Two types of soils are considered: homogeneous and non-homogeneous/heterogeneous. The heterogeneous soil consists of a metallic plate in contact with a parallelepiped tank filled with water or wetted sand of different conductivities. It is shown that, for homogeneous Earth, the $\mathrm{U}_{50 \%}$ decreases when increasing the soil conductivity and the electrodes gap decreases. For heterogeneous soil configuration and a given distance from the $\mathrm{HV}$ electrode to the metallic electrode, the $\mathrm{U}_{50 \%}$ is higher for lower conductivities of homogeneous soil.
\end{abstract}

Key words: Lightning discharge, soil conductivity, electrode gap, homogeneous Earth, heterogeneous Earth, $\mathrm{U}_{50 \%}$ breakdown voltage

\section{INTRODUCTION}

It is well known that the electro-geological properties of soil and its topography and the structure at the ground have a great influence on the impact points of lightning strikes (lightning density or yet, the number of lightning impacts $/ \mathrm{km}^{2}$ year) (Uman, 1987). This latter (lightning density) serves as a basis for the design of lightning protection systems. The main electro-geological parameters that greatly influence the zones of lightning protection and the induced effects on earthen structures are the conductivity and dielectric permittivity of soil.

Many experimental studies have been conducted on the influence of soil conductivity on the effectiveness of lightning protection systems (i.e., the capture zone). It was reported that the protection effectiveness increases when decreasing the soil conductivity (Anderson, 1980; Nixon et al., 2000; Szpor, 1971, 1973, 1974; Noskov et al., 2000). In their experimental modeling of lightning strike in soil (Fortov et al., 2016) showed that the discharge current amplitude increases when the soil conductivity increases. The soil conductivity plays a role both in the distortions of radiated field as well as in coupling of field to overhead line (Kannu and Thomas, 2000; Li et al., 2000). Indeed, soil conductivity has a bearing on the potential gradients that are to be expected at the soil surface during times of fault current through the Earth electrode (Kannu and Thomas, 2000). When analyzing the induced voltage on an over-head line due to an indirect lightning stroke, (Kannu and Thomas, 2000) showed that the ground conductivity influences both the electric field as well as the coupling mechanism and hence, the magnitude and wave shape of the induced voltage.

In general, the soil is not a homogeneous medium because of the variation of water content and also because of the variation in grain size and the existence of organic and man-made debris, especially, in urban centers or surrounding. Thus, its conductivity is not constant; it depends on its composition, the depth from the surface and with the temperature of soil what explains the wide variance of conductivity from place to place and over time. However, for the design of lightning protection systems and calculating the impedance of an Earth electrode, one generally, assumes that the soil as a homogeneous medium to make easier the analysis and comparison of results. Under laboratory conditions, soil samples are simulated by water of different conductivities and water in samples (sand for instance) reasonably well-mixed. This study is aimed at the influence of soil conductivity and electrode gaps on both positive and negative lightning discharge current and $\mathrm{U}_{50 \%}$ breakdown

Corresponding Author: Usama Khaled, Department of Electrical Engineering, College of Engineering, King Saud University, 
voltage. The experiments are conducted on two laboratory experimental models: the first one representing a homogeneous soil and the second one a heterogeneous one. For homogeneous soil, a wide range of conductivities reflecting different types of soils were considered: $15-800 \mu \mathrm{S} / \mathrm{cm}^{-1}$.

\section{MATERIALS AND METHODS}

The Lightning Impulse (LI) voltage is supplied by a $1 \mathrm{MV}-40 \mathrm{~kJ}-1.2 / 50 \mu \mathrm{sec}$ Marx generator (Haefely type) connected to a dedicated capacitive divider. The $\mathrm{U}_{50 \%}$ breakdown voltage is determined by the up-and-down method on series of 10 impulse shots, according to IEC 60060 ed3 2010-09 (International Electrotechnical

(a)
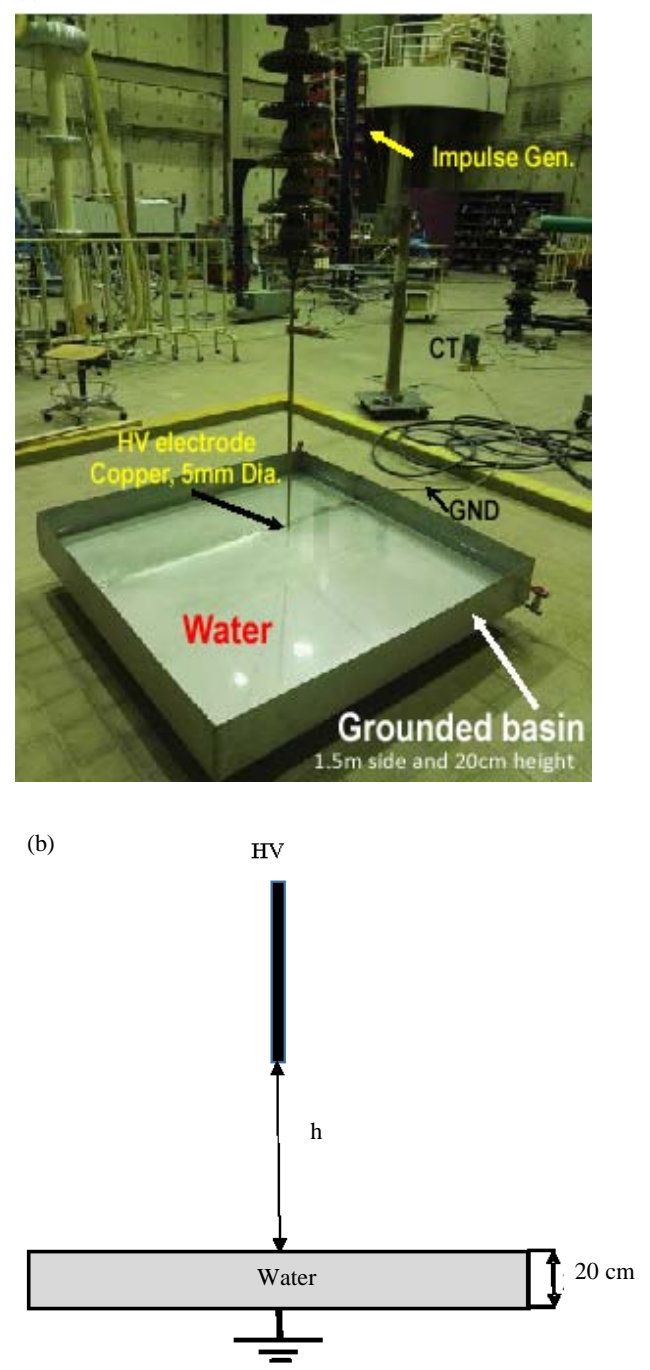

Fig. 1: Rod-plane arrangement with homogeneous Earth: a) General view and b) Scheme of experimental arrangement
Commission). The tests are conducted at normal conditions (pressure, temperature and humidity). The HV electrode consists of a cooper rod of $100 \mathrm{~cm}$ length and $10 \mathrm{~mm}$ diameter ended by a hemisphere of $5 \mathrm{~mm}$ of radius. The High Voltage (HV) electrode (i.e., the rod) and Earth gap distance $h$ varies between 0.5 and $40 \mathrm{~cm}$.

Two laboratory experimental models were used to simulate homogeneous and heterogeneous Earths, respectively. The first one simulating a homogeneous Earth consists of a metallic parallelepiped tank of $1.5 \times 1.5 \mathrm{~m}$ sides and $0.20 \mathrm{~m}$ height the bottom of which is grounded as shown in Fig. 1. This tank is filled with water or wetted sand of different conductivities that simulates the Earth. The different conductivities are obtained by adding different concentrations of salt to demineralized and de-ionized water. The conductivities we investigated are: $15,165,360$ and $800 \mu \mathrm{Scm}^{-1}$.

The second laboratory experimental model simulating the heterogeneous Earth is constituted by two parts: a similar tank filled with water or wetted sand as that used for homogeneous Earth adjacent to a square metallic copper plate, $1.5 \times 1.5 \times 0.05 \mathrm{~m}$ of the same surface as that of water as shown in Fig. 2 the metallic plate simulates the good conducting Earth. The rod is placed above the
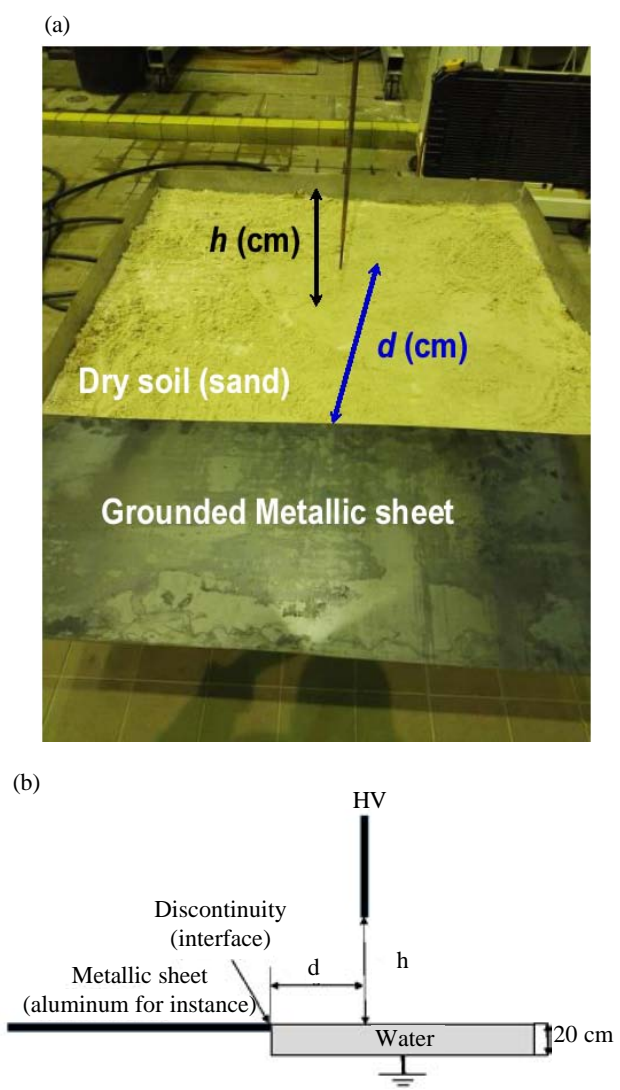

Fig. 2: Rod-plane arrangement with heterogeneous Earth 
heterogeneous structure at different distances from the interface of both surfaces as indicated on Fig. 2b.

\section{RESULTS AND DISCUSSION}

Homogeneous Earth case: Figure 3 depicts the $U_{50 \%}$ Breakdown Voltage (BDV) versus the electrode gap distance for different conductivities of soil for both positive and negative polarities of voltage and Fig. 4 gives the variation of $\mathrm{U}_{50 \%} \mathrm{BDV}$ as a function of soil conductivity for different electrodes gaps. We observe that the $\mathrm{U}_{50 \%} \mathrm{BDV}$ increases with electrode gap for a given soil conductivity (Fig. 3) and decreases when the conductivity of soil increases (Fig. 4) whatever the polarity of voltage. However, for given soil conductivity and electrode gap, the negative $\mathrm{U}_{50 \%} \mathrm{BDV}$ is higher than
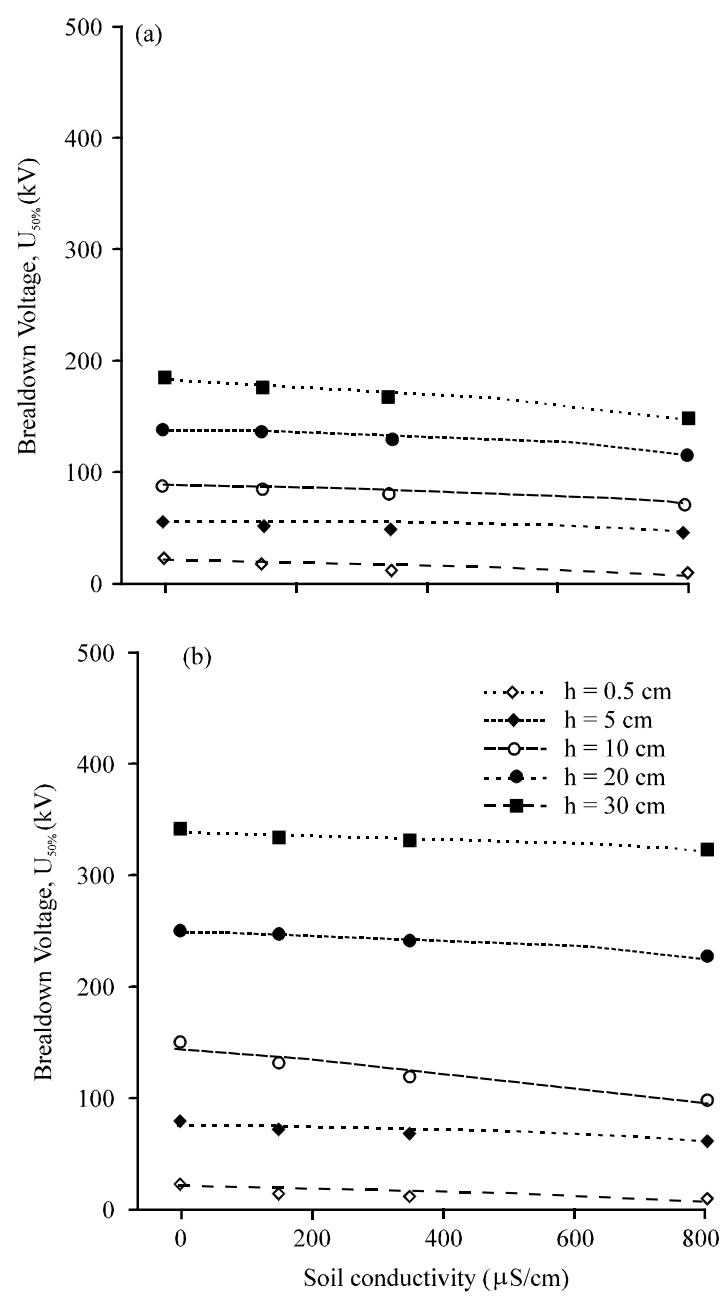

Fig. 3: $\mathrm{U}_{50 \%}$ breakdown voltage vs. the electrode gap for different conductivities of homogeneous earth for both: a) Positive and b) Negative polarities the positive one (Fig. 4). By plotting the straight lines fitting the tendency of the variation of $\mathrm{U}_{50 \%} \mathrm{BDV}$, the slope of these straight lines are of about 5 and $10 \mathrm{kV} / \mathrm{cm}$ for positive and negative polarities, respectively. For a given conductivity, one can deduce the following relationships for air gaps we investigated $(5-40 \mathrm{~cm})$ for positive polarity:

$$
\mathrm{U}_{50 \%}=500 \mathrm{~h}(\mathrm{kV}, \mathrm{m})
$$

And for negative polarity:

$$
\mathrm{U}_{50 \%}=1000 \mathrm{~h}(\mathrm{kV}, \mathrm{m})
$$
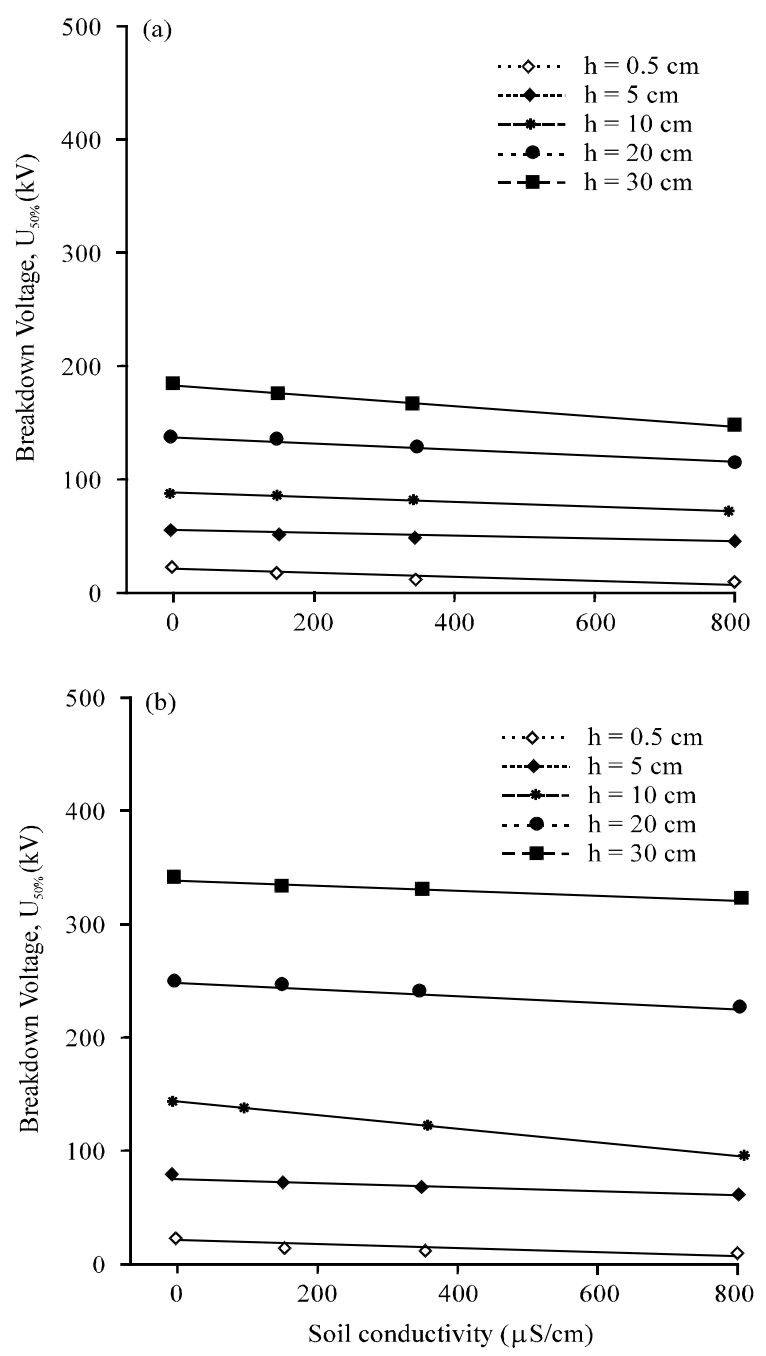

Fig. 4: $U_{50 \%}$ breakdown voltage vs. soil conductivity for different electrodes gaps: a) Positive polarity and b) Negative polarity 


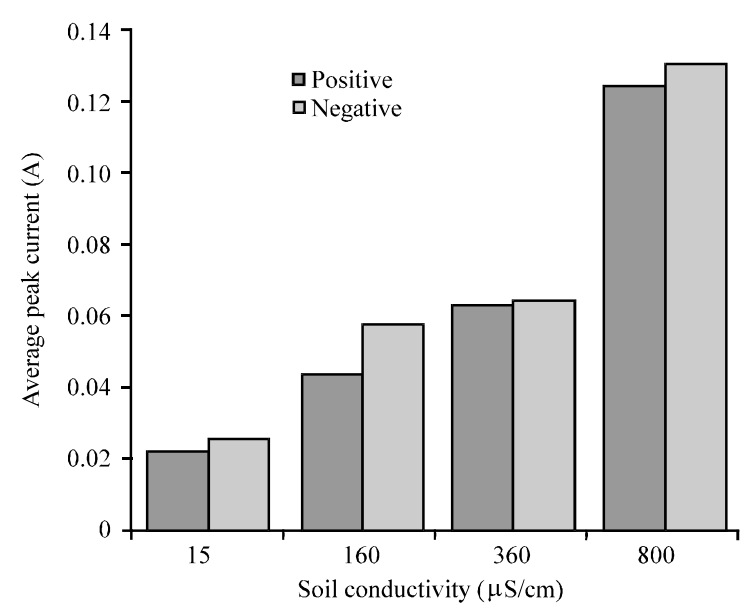

Fig. 5: Comparison of the average peak current vs. the Earth conductivities for both positive and negative polarities for a gap distance $h$ of $10 \mathrm{~cm}$

A linear variation for standard positive lightning impulse voltage $(1.2 / 50 \mu \mathrm{sec})$ has been also, proposed for air gaps of several $\mathrm{m}$ with a metallic grounded electrode. These authors proposed an empirical relationship for $\mathrm{U}_{50 \%}$ BDV for a point-plane electrode arrangement of the shape:

$$
\mathrm{U}_{50 \%}=510 \mathrm{~h}(\mathrm{kV}, \mathrm{m})
$$

This equation is very close to that we deduced. For negative polarity observed that the linearity is maintained up to gaps of $5 \mathrm{~m}$ and then there is a slight tendency to saturation.

The decrease of $\mathrm{U}_{50 \%} \mathrm{BDV}$ vs. the Earth conductivity is also, quasi-linear. Thus, one can similarly deduce relationships that give the variation of $\mathrm{U}_{50 \%} \mathrm{BDV}$ vs. the Earth conductivity $\sigma$. For a given point-plane electrodes gap h, it yields for positive point:

$$
\mathrm{U}_{50 \%}=\mathrm{k}_{+} \sigma+181(\mathrm{kV}, \mathrm{S} / \mathrm{m})
$$

where, $\mathrm{k}=-764 \mathrm{kV} \cdot \mathrm{m} / \mathrm{sec}$. And for negative point:

$$
\mathrm{U}_{50 \%}=\mathrm{k} . \sigma+345(\mathrm{kV}, \mathrm{S} / \mathrm{m})
$$

where, $\mathrm{k}=-510 \mathrm{kV} \cdot \mathrm{m} / \mathrm{sec}$. The above relationships can be useful for the design/dimensioning of air insulating structures.

On the other hand, the average peak current increases with soil conductivity. Figure 5 summarizes the experimental results of average peak current versus the
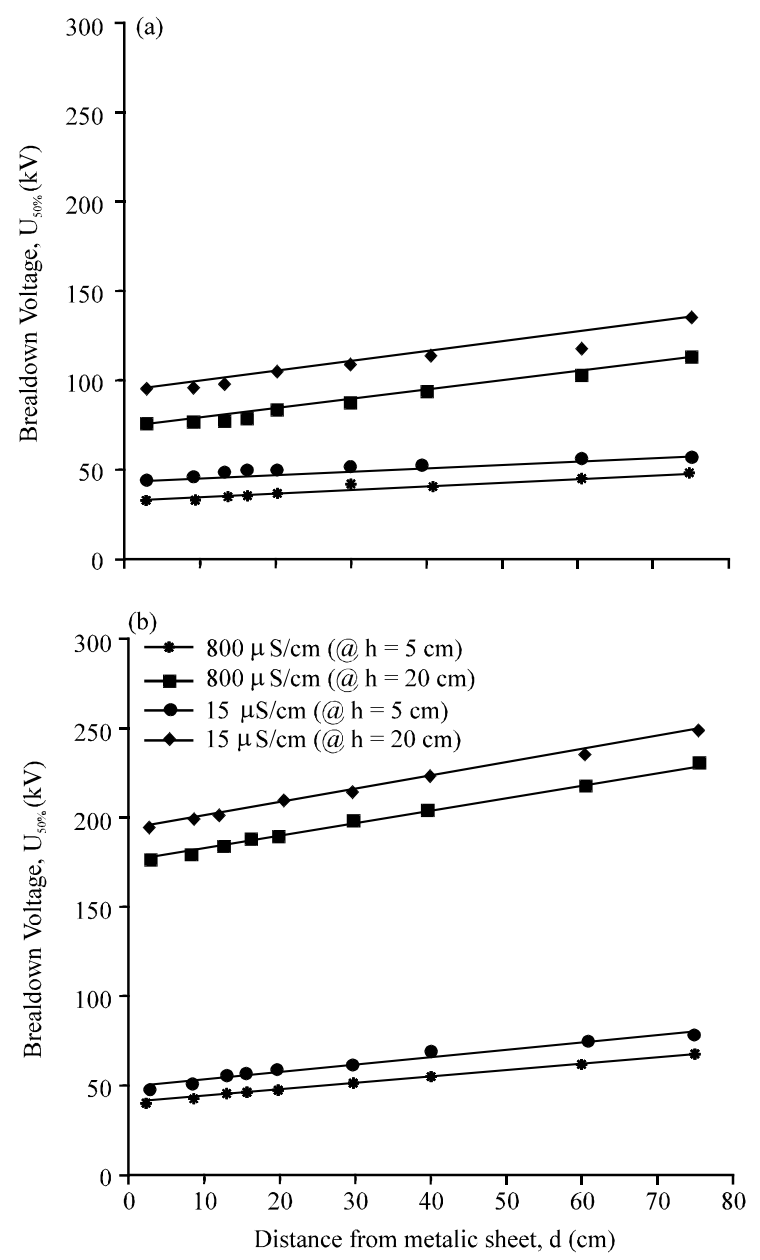

Fig. 6: $U_{50 \%}$ breakdown voltage vs. the electrode gap for different conductivities of heterogeneous earth for both: a) Positive and b) Negative polarities

Earth conductivities for both positive and negative polarities for a gap distance of $10 \mathrm{~cm}$. We observe that the negative currents are slightly higher than the positive ones.

The above results confirm those obtained by others for lightning discharges. Indeed, it was reported that the leader and return stroke current increase and the time delay of the arc phase decreases when the soil conductivity increases (Beroual and Fofana, 2002, 2016) what explains the fact that the higher the soil conductivity, the higher the number of lightning strikes is (Aguet and Ianoz, 1987) the large soil conductivity would increase lightning flash density. According to observations reported in literature, the lightning strikes have a preferential attraction to the humid soil and clothes and swamp ground (Zeddam and Degauque, 1987). The 


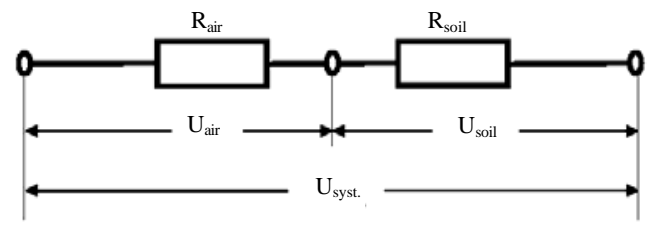

Fig. 7: Equivalent electrical circuit of Fig. 1

observations according which the high voltage lines are often the subject of lightning strikes find, here, some confirmation.

Hetrogeneous Earth case: The $\mathrm{U}_{50 \%} \mathrm{BDV}$ is influenced by the distance from the HV rod electrode to the interface. For given electrode gap and soil conductivity, $\mathrm{U}_{50 \%} \mathrm{BDV}$ increases when the $\mathrm{HV}$ electrode moves away from the boundary between both surfaces as shown in Fig. 6. And for a given distance $\mathrm{d}$ and electrode gap $\mathrm{h}$, the $\mathrm{U}_{50 \%}$ breakdown voltage is higher with lower soil conductivity (i.e., bad Earth), whatever the polarity. On the other hand, for the same geometrical parameters ( $h$ and $d$ ) and the same soil conductivity, the negative $U_{50 \%}$ breakdown voltage is higher than the positive ones. These results show that the attractiveness of lightning strikes and thence the strikes density depends on the geological structure of regions/zones and their conductivity.

By using an RLC equivalent circuit model describing the whole lightning discharge propagation up to breakdown, (Beroual and Fofana, 2002, 2016) showed that for given experimental conditions and air gap, the higher the soil conductivity, the lower the breakdown voltage is. This model being time consuming, we can use a simple model/approach to show the influence of soil conductivity on breakdown voltage of air gaps. For that purpose, consider Fig. 7 which is the equivalent electrical circuit of Fig. 1.

Where, $U_{\text {air }}$ is the voltage at the air gap and $U_{\text {soil }}$ the voltage drop at the soil layer; $R_{\text {air }}$ and $R_{\text {soil }}$ are the resistances of air gap and soil layer, respectively. When the breakdown occurs, $\mathrm{R}_{\mathrm{arr}}$ and $\mathrm{R}_{\text {soil }}$ will be the resistances of discharge channel in air and in soil, respectively. Thus, the voltage at the whole system $\mathrm{U}_{\text {syst }}$ will be:

$$
\mathrm{U}_{\text {syst. }}=\mathrm{U}_{\text {air }}+\mathrm{U}_{\text {soil }}
$$

Knowing that for given electrodes geometry and atmospheric conditions (pressure, temperature and humidity), the breakdown voltage $U_{\text {air }}$ of a given air gap in case of metallic electrodes assumed to perfect conductor, is constant, the voltage $U_{\text {syst }}$ which must be applied to our configuration/system for breakdown to occur will depend on the voltage drop at the soil layer $\mathrm{U}_{\text {soil }}$. If soil is a perfect

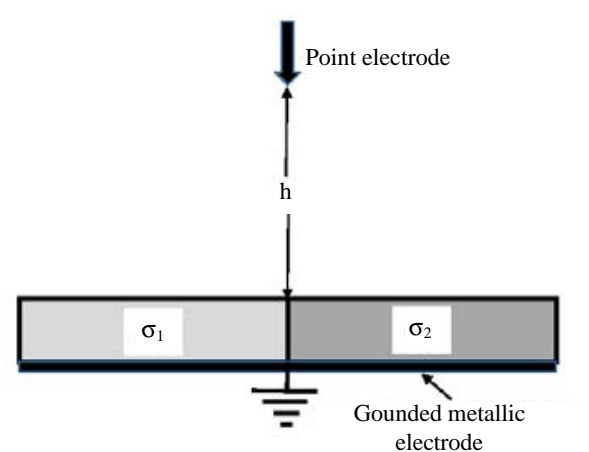

Fig. 8: Schematic diagram of heterogeneous soil corresponding to Fig. 2 for $\mathrm{d}=0$

conductor, $\mathrm{U}_{\text {soil }}=0$ and $\mathrm{U}_{\text {syst }}=\mathrm{U}_{\text {air }}$. Otherwise, if the conductivity of soil decreases, the resistance $R_{\text {soil }}$ will increase (the soil is less conducting) and consequently, the voltage $\mathrm{U}_{\text {soil }}$ increases. This results in an increase of $\mathrm{U}_{\text {syst. }}$ Thus, the more conducting the soil, the lower the voltage that must be applied for breakdown to occur:

$$
\begin{aligned}
& \sigma_{\text {soil }} \text { increases } \geq R_{\text {soil }} \text { decreases } \geq U_{\text {soil }} \text { decreases } \geq \\
& U_{\text {syst }} \text { decreases }
\end{aligned}
$$

In case of heterogeneous soil (Fig. 2a) with high voltage electrode above the boundary of both surfaces of different conductivities, $\sigma_{1}$ and $\sigma_{2}$ (i.e.; $\mathrm{d}=0$ ) as shown in Fig. 8, we can conclude that:

$$
\begin{aligned}
& \mathrm{U}_{\text {syst }}\left(\sigma_{1}\right)=\mathrm{U}_{\text {air }}+\mathrm{U}_{\text {soil }}\left(\sigma_{1}\right) \\
& \mathrm{U}_{\text {syst }}\left(\sigma_{2}\right)=\mathrm{U}_{\text {air }}+\mathrm{U}_{\text {soil }}\left(\sigma_{2}\right)
\end{aligned}
$$

Thus, if:

$$
\sigma_{2}>\sigma_{1} \geq \mathrm{U}_{\text {soil }}\left(\sigma_{2}\right)<\mathrm{U}_{\text {soil }}\left(\sigma_{1}\right) \geq \mathrm{U}_{\text {syst }}\left(\sigma_{2}\right)<\mathrm{U}_{\text {syst }}\left(\sigma_{1}\right)
$$

Therefore, the breakdown voltage of system with soil of higher conductivity will occur before that with soil of lower conductivity. The discharge goes to the most conductive ground. One can conclude that the lightning discharges strikes are more attracted by the most conductive soil what is confirmed by our results and by those reported in literature.

\section{CONCLUSION}

In this research we showed that the conductivity of soil greatly influences the lightning breakdown voltage of electrodes gap and current in both positive and negative polarities. In case of homogeneous soil, the breakdown voltage increases when decreasing the conductivity of 
soil and the electrodes gap increases, whatever the polarity. The average peak current increases with soil conductivity. Also, for given soil conductivity and electrodes gap, both negative current and breakdown voltage are higher than the positive ones.

For heterogeneous soil configuration, the breakdown voltage depends on the position of $\mathrm{HV}$ electrode with respect to the interface. For a given distance from the $\mathrm{HV}$ electrode to the metallic electrode, the $\mathrm{U}_{50 \%}$ is higher for lower conductivities of homogeneous soil. The attractiveness of lightning strikes and thence the strikes density depend on the conductivities of soils and thence on the geological structure of regions/zones.

\section{ACKNOWLEDGEMENT}

The researchers extend their appreciation to the Deanship of Scientific Research at King Saud University for funding this research through the Undergraduate Research Support Program, Project No. (URSP-3-17-42)

\section{REFERENCES}

Aguet, M. and M. Ianoz, 1987. Haute Tension. 2nd Edn., DunodPublisher, Paris, France, ISBN:9782880740627, Pages: 425.

Anderson, R.B., 1980. Lightning parameters for engineering application. Electra, 69: 65-102.

Beroual, A. and I. Fofana, 2002. Influence of soil conductivity on the positive lightning impulse current. Proceedings of the 26th International Conference on Lightning Protection (ICLP'2002), September 2-6, 2002, Krakow, Poland, pp: 65-70.

Beroual, A. and I. Fofana, 2016. Discharge in Long Air Gaps: Modelling and Applications. IOP Publishing, Bristol, UK., ISBN-13:978-0750312370, Pages: 245.

Fortov, V.E., V.P. Smirnov, E.E. Son, Y.A. Bykov and E.V. Grabovskiy et al., 2016. Experimental modeling of lightning strike in soil. J. Phys. Conf. Ser., 774: 1-7.
Kannu, P.D. and J. Thomas, 2000. Influence of ground conductivity on the over voltages induced on overhead power distribution lines due to an indirect lightning stroke. Proceedings of the IEEE International Symposium on Electromagnetic Compatibility (Cat. No. 00CH37016) Vol. 2, August 21-25, 2000, IEEE, Washington, DC., USA., pp: 949-954.

Li, L., X. Cui, T. Lu and H. Yin, 2000. Influence of soil and conductor of ground grid on safety of the grounding system. Proceedings of the IEEE International Symposium on Electromagnetic Compatibility (Cat. No. 00CH37016), August 21-25, 2000, IEEE, Washington, DC, USA., pp: 675-679.

Nixon, K.J., I.R. Jandrell and H.J. Geldenhuys, 2000. Sensitivity analysis of parameters influencing the lightning impulse current behaviour of Earth electrode components. Proceedings of the 25th International Conference on Lightning Protection (ICLP), September 18-22, 2000, ICLP Centre, Rhodes, Greece, pp: 484-489.

Noskov, M.D., O.I. Pleshkov and V.V. Lopatin, 2000. Computer modelling of Earth conductivity and relief effects on lightning orientation. Proceedings of the 25th International Conference on Lightning Protection (ICLP), September 18-22, 2000, ICLP Centre, Rhodes, Greece, pp: 389-394.

Szpor, S., 1971. International comparison of lightning current crest-value records. Arch. Elektrotech, 20: 379-392.

Szpor, S., 1973. Topography and frequency of lightning. Arch. Elektrotechn, 22: 735-749.

Szpor, S., 1974. Earth voltages for back flash-overs. Arch. Elektrotchn, 23: 1001-1009.

Uman, M.A., 1987. The Lightning Discharges. 1st Edn./Vol. 39, Academic Press Publishing Company, Cambridge, Massachusetts, USA., ISBN : 9780080959818, Pages: 377.

Zeddam, A. and P. Degauque, 1987. Current and voltage induced on telecommunication cables by a lightning stroke. Electromagnet., 7: 541-564. 